\title{
THE METHODS OF JUSTIFICATION OF SELECTION OF EFFICIENT REAGENTS FOR THE DRILLING PROCESS FLUID
}

\author{
• • в вчиников, • • емененко, • • в вчиников \\ V. P. Ovchinnikov, A.F. Semenenko, P. V. Ovchinnikov \\ юменский индустри льный университет, г. юмень \\ " уров я техник» (), г. оскв \\ лючевые слов : промывочн я жидкость, биополимеры; ст билиз торы; \\ см зыв ющие ре генты \\ Key words: flushing liquid; biopolymers; stabilizers; lubricating agents
}

звестно, что основн я проблем , котор я требует своего решения это обеспечение сохр нности фильтр ционно-емкостных свойств, вскрыв емых в процессе бурения коллекторов нефти и г 3 . н , в основном, реш ется подбором сост в промывочной жидкости с требуемыми для этих целей физико-мех ническими свойств ми. последнее время, с учетом изложенного, н шли и н ходят широкое применение буровые $\mathrm{p}$ cтворы с использов нием полимеров, более эффективны биополимеры. ледует отметить, что последние ч ще всего используются для регулиров ния отдельных свойств p створ . в в сост ве бурового р створ «Polyxan-H1» биополимер Polyxan для повышения его термостойкости, для снижения пок 3 теля фильтр тоотд чи вводят низковязкий модифициров нный кр хм л Flo-Xan или Bohramyl, не исключено применение кольм тирующего м тери л , н пример мр морной крошки. сост ве бурового p створ Polyxan-H2 используют высоко и низковязкую поли нионную целлюлозу ( - , - ), для регулиров ния щелочности - к льциниров нную соду. сост в х полимерглинистых буровых р створов Floxan-L, PolybEnt, Bentoflocx-L и другие, рекомендов ны « олибент» - полимеры ст билиз торы - , -

, DF-Flock, биополимеры Polyxan, p зжижители, см зыв ющие ре генты и т. д. [1]. о же с мое отмеч ется и в других, используемых сост в х промывочных жидкостях [2]. ри этом необходимо отметить, что используемые высокомолекулярные соединения, в силу своего химического сост в ок зыв ют влияние не только н один пок 3 тель, , к к пр вило, н несколько. пример, н пок з тель фильтр ции, эффективную вязкость, ст тическое и дин мическое н пряжение сдвиг, ст бильность и т. д. стественно число пок з телей для к ждого полимер и интенсивность воздействия будет p зличным. иболее эффективным и перспективным полимером будет тот, который ок зыв ет свое воздействие н большее число п р метров и это воздействие более интенсивно, обеспечив ется меньшее содерж ние ре гентов и их количество. се это требует р зр ботки определенной методики н пр вленной н решение пост влено з д чи.

читыв я изложенное, предл г ется следующее:

- осуществляется сбор имеющихся сведений по используемым н иболее ч сто ре гент м (доб вк м, м тери л м);

- по результ т м эксперимент льных исследов ний определяется з висимость влияния ре гент н к ждый из изуч емых п р метров р створ . этом случ е можно воспользов ться методом регрессионного н лиз ;

- н полученную з висимость (ур внения регрессии) н кл дыв ются гр ничные (нормируемые) пок з тели, которым последний должен соответствов ть. то или результ ты требов ний $\quad$, или результ ты опрос специ листов и т. д.;

- $\quad$ в р мк х уст новленных гр ниц определяют оптим льную концентр цию ре гент ;

- проводится н лиз полученных сведений с целью выявления количеств регулируемых ре гентом п р метров в предел х принятых гр ниц и их содерж ние;

- осуществляется выбор н иболее эффективного ре гент и его оптим льного содерж ния с учетом н ибольшего числ регулируемых п р метров в предел х д нной концентр ции.

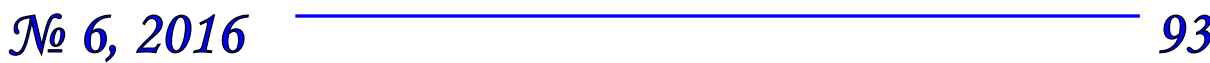


нную процедуру более н глядно можно предст вить н следующем примере, взяв сведения из $\mathrm{p}$ боты [3-5]. д нной р боте приведены результ ты л бор торных исследов ний по изучению порядк восемн дц ти полимерных ре гентов н физикомех нические п р метры р створов с их применением - условную вязкость ( ); пок 3 тель фильтр ции $\left(\phi_{30}\right)$; ст тическое н пряжение сдвиг после одной минуты, десяти минут покоя $\left(\theta_{1 / 10}\right)$; эффективную вязкость р створ $(\eta)$; дин мическое н пряжение сдвиг $\left(\tau_{0}\right)$; по реологическим пок 3 телям р ссчит н коэффициент нелинейности модели движения поток (n). боснов ние по н иболее эффективному ре генту отсутствует или предст влено в неявной форме.

соответствии с предложенным лгоритмом решение для к ждого п р метр , к ждого ре гент построены з висимости влияния содерж ния ре гент н величину п $\mathrm{p}$ метр . рис. 1 предст влен один из гр фиков д нной з висимости. о результ т м опрос ряд известных специ листов в обл сти буровых р створов уст новлены следующие обл сти допустимых величин изуч емых п р метров, при которых достиг ются высокие пок з тели сохр нности фильтр ционно-емкостных свойств продуктивного пл ст .

то для $-30 \ldots 50 \mathrm{c} ; \phi_{30}-6 \ldots 8 \mathrm{~cm}^{3} / 30$ мин; $\theta_{1}-15 \ldots 60$ д $; \theta_{10}-20 \ldots 65$ д ; $\eta-10 \ldots 20 \quad ; \tau_{0}-80 \ldots 100$ д $; \mathrm{n}-0,3 \ldots 0,5 ; \mathrm{p}-6 \ldots 9$.

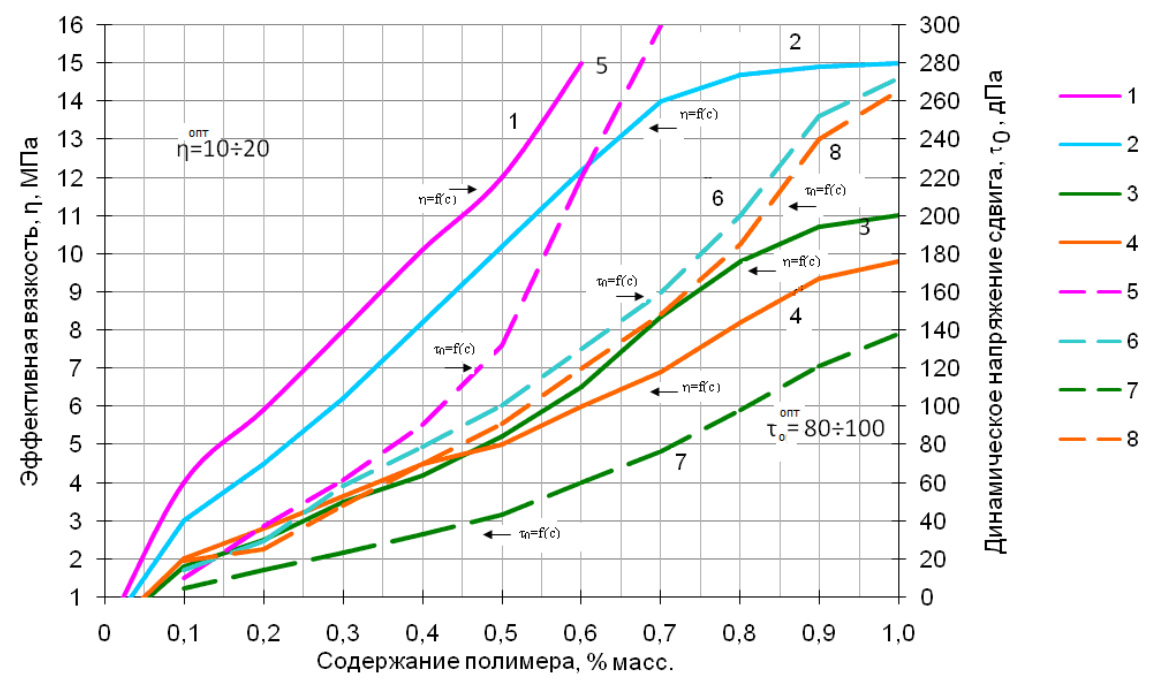

ис. 1. висимости зн чений п рлетров (эффективн я вязкость, н пряжение сдвиг $\tau_{0}$ ) от содерж ния полимеров; сплошн я-эффективн я вязкость $\eta=f(c)$, пунктирн $я-$ ин мическое н пряжение сдвиг $\tau_{0}=f(c)$

к 3 нные «нормиров нные» их зн чения н носятся н гр фические 3 висимости, по которым определяются требуемые концентр ции полимеров. ч стности н рисунке предст влены $з$ висимости зн чений п р метров эффективной вязкости и дин мического н пряжения сдвиг для ряд полимеров: 1 - иокс н (производств

« етр »);2 - мм кс н (производств « мм - им»); 3 - Biovis (производств SKW «Polymep», ерм ния); 4 - Xanthan Gum IV (производств CNPC, ит й). сего про н лизиров но 18 видов полимеров р зличных з водов производителей (российских и з рубежных). к видно из предст вленных з висимостей содерж ние полимер и его вид влияет н р ссмотренные пок з тели. ри этом т кже меняется и их концентр ции, при которых достиг ются требуемые п р метры р створ . сходя, из этого н логично были построены з висимости других п р метров от вид и содерж ния ре гент. езульт ты их совместного н лиз позволяет выявить обл сти зн чений концентр ций полимеров, при которых можно обеспечить три, четыре, пять п р метров р створ с требуемыми зн чениями, что позволяет обоснов ть вид н иболее эффективных ре гентов и их «оптим льное» содерж ние (т бл. 1). 
езульт ты н лиз влияния полимеров н основные $n$ р метры р створов

\begin{tabular}{|c|c|c|c|c|c|}
\hline \multirow[t]{2}{*}{$\begin{array}{l}\text { 3в - } \\
\text { ние }\end{array}$} & \multirow[t]{2}{*}{ р метр } & \multirow[t]{2}{*}{$\begin{array}{l}\text { птим льное содерж ние полимер для } \\
\text { обеспечения нормируемого зн чения } \\
\text { п р метр }\end{array}$} & \multicolumn{2}{|c|}{$\begin{array}{l}\text { р метры, регулируемые } \\
\text { в предел х нормируемых } \\
\text { зн чений }\end{array}$} & \multirow{2}{*}{\begin{tabular}{|c|}
$\begin{array}{c}\text { бщее } \\
\text { количество } \\
\text { регулируемых } \\
\text { П р метров }\end{array}$ \\
1 \\
\end{tabular}} \\
\hline & & & $0,75-1,0$ & $\mathrm{p}$ & \\
\hline \multirow{7}{*}{ 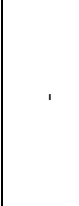 } & $\eta$ & 0,75 & $>0,85-0,75$ & $\mathrm{p}, \eta$ & 2 \\
\hline & $\tau_{0}$ & $0,35=0,42$ & $0,50-0,65$ & $\mathrm{p}, \mathrm{\eta}, \mathrm{n}$ & 3 \\
\hline & $\mathrm{p}$ & & $0,42-0,50$ & $\mathrm{p},, \tau_{0}, \mathrm{n}$ & 4 \\
\hline & $\mathrm{n}$ & 0,65 & $0,35-0,42$ & $\mathrm{p}, \eta, \quad$, & 5 \\
\hline & & $0,35 \geq 0,50$ & $0,30-0,35$ & $\mathrm{p},, \mathrm{n}$ & 3 \\
\hline & & & $0,25-0,3$ & $\mathrm{p}, \mathrm{n}$ & 2 \\
\hline & & & $0,1-0,25$ & $\mathrm{p}$ & 1 \\
\hline \multirow{9}{*}{$\begin{array}{l}x \\
\ddot{y} \\
y\end{array}$} & & 0,3 & $0,76-1,0$ & $\eta, p$ & 2 \\
\hline & $\eta$ & 0,55 & $0,65-0,76$ & $\eta, \mathrm{p}, \mathrm{n}$ & 3 \\
\hline & $\tau_{0}$ & 0,411 & $0,55-0,65$ & $, \eta, p, n$ & 4 \\
\hline & $\mathrm{p}$ & & $0,50-0,55$ & $, \mathrm{p}, \mathrm{n}$ & 3 \\
\hline & $\mathrm{n}$ & 0,18 & $0,41-0,50$ & $, \tau_{0}, \mathrm{p}, \mathrm{n}$ & 5 \\
\hline & & 0,33 & $0,33-0,41$ & $, \mathrm{p}, \mathrm{n}$, & 4 \\
\hline & & & $0,30-0,33$ & $, \mathrm{p}, \mathrm{n}$ & 3 \\
\hline & & & $0,18-0,3$ & $\mathrm{p}, \mathrm{n}$ & 2 \\
\hline & & & $0,1-0,18$ & $\mathrm{p}$ & 1 \\
\hline \multirow{8}{*}{$\frac{n}{2}$} & & 0,68 & $0,81-1,0$ & ,n & 2 \\
\hline & $\eta$ & 0,15 & $0,71-0,81$ & $, \tau_{0}, \mathrm{n}$ & 3 \\
\hline & $\tau_{0}$ & $0,7 1 \longdiv { 0 , 8 1 }$ & $0,68-0,7$ & ,n & 2 \\
\hline & $\mathrm{p}$ & 0,42 & $0,65-0,68$ & $\mathrm{n}$ & 1 \\
\hline & $\mathrm{n}$ & 0,48 & $0,46-0,65$ & $\mathrm{n}$, & 2 \\
\hline & & 0,42 & $0,42-0,48$ & & 1 \\
\hline & & & $0,15,0,42$ & $\mathrm{p}$ & 1 \\
\hline & & & $0,1-0,15$ & $\eta, p$ & 2 \\
\hline \multirow{8}{*}{ 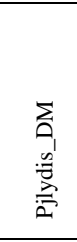 } & & $0,48 \backslash 0,52$ & $0,8-1,0$ & $\mathrm{p}$ & 1 \\
\hline & $\eta$ & 0,3 & $0,75-0,8$ & $\eta, p$ & 2 \\
\hline & $\tau_{0}$ & $0,25=0,30$ & $0,6-0,75$ & $\eta, \mathrm{p}, \mathrm{n}$ & 3 \\
\hline & $\mathrm{p}$ & & $0,52-0,6$ & $\eta, \mathrm{p}, \mathrm{n}$ & 4 \\
\hline & $\mathrm{n}$ & 0,25 & $0,48-0,52$ & $, \eta, p, n$, & 5 \\
\hline & & 0,25 & $0,30-0,48$ & $\eta, p, n$ & 4 \\
\hline & & & $0,25-0,3$ & $\tau_{0}, \mathrm{p}, \mathrm{n}$, & 4 \\
\hline & & & $0,1-0,25$ & $\mathrm{p}$ & 1 \\
\hline \multirow{7}{*}{ 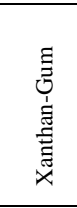 } & & $0,6=0,66$ & $0,66-1,0$ & $\mathrm{p}$ & 1 \\
\hline & $\eta$ & & $>0,6-0,66$ &,$p$ & 2 \\
\hline & $\tau_{0}$ & $0,0,46-10,52$ & $0,52-0,6$ & $\mathrm{p}$ & 1 \\
\hline & $\mathrm{p}$ & & $0,46-0,52$ & $\tau_{0}, \mathrm{p}$ & 2 \\
\hline & $\mathrm{n}$ & 0,42 & $0,42-0,46$ & $\mathrm{p}$ & 2 \\
\hline & & - 0,52 & $0,31-0,42$ & $\mathrm{p}, \mathrm{n}$, & 3 \\
\hline & & & $0,1-0,31$ & $p, n$ & 2 \\
\hline \multirow{7}{*}{ 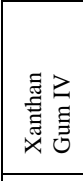 } & & 0,85 & $0,85-1,0$ & $p$ & 1 \\
\hline & $n$ & & $>0.7-0.85$ &.$p$ & 2 \\
\hline & $\tau_{0}$ & $0.46-0.52$ & $0.52-0.7$ & $\mathrm{p}$ & 1 \\
\hline & $\mathrm{p}$ & & $0,46-0,57$ & $\tau_{0}, \mathrm{p}, \mathrm{n}$ & 4 \\
\hline & $n$ & 0.39 & $0.39-0.46$ & $\mathrm{p}, \mathrm{n}$ & 3 \\
\hline & & 0.52 & $0.3-0.39$ & $p$ & 2 \\
\hline & & & $0,1-0.3$ & $\mathrm{p}$ & 1 \\
\hline & & $0,72-076$ & $0,8-1,0$ & $n, n$ & 2 \\
\hline & $\mathrm{n}$ & 0.8 & $0.76-0.8$ & $\mathrm{n}$ & 1 \\
\hline & $\tau_{0}$ & 0,72 & $0,72-0,76$ &, $\mathrm{n}$ & 2 \\
\hline & $\mathrm{p}$ & 0.4 & $0.65-0.72$ & $\tau_{0} \mathrm{n}$ & 2 \\
\hline & $\mathrm{n}$ & & $0.6-0.65$ & $\tau_{0} \mathrm{n}$ & 3 \\
\hline$\frac{\pi}{0}$ & & 0.35 & $0.4-0.6$ & $\mathrm{n}$. & 2 \\
\hline$\ddot{n}$ & & & $0,35-0,4$ & $\mathrm{p}, \mathrm{n}$, & 3 \\
\hline & & & $0.1-0.35$ & $p \cdot n$ & 2 \\
\hline & & 0.6 & $0.85-1.0$ & $n$ & 1 \\
\hline อి & $n$ & 0,5 & $0,8-0,85$ & $\eta$ & 3 \\
\hline$x$ & $\tau_{0}$ & 0.6 & $0.6-0.8$ &.$n$. & 3 \\
\hline é & $\mathrm{p}$ & 10.35 & $0.5-0.6$ & n. $\tau_{0}$ & 2 \\
\hline 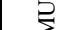 & $\mathrm{n}$ & $-10,45$ & $0,45-0,5$ & - & - \\
\hline 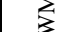 & & 0.60 & $0.35-0.45$ & $\mathrm{n}$ & 1 \\
\hline$\infty$ & & & $0.18-0.35$ & $p \cdot n$ & 2 \\
\hline & & & $0,1-0,18$ & $\mathrm{p}$ & 1 \\
\hline & & 0,60 & $0,8-1,0$ & $\eta$ & 1 \\
\hline & $n$ & 0.60 & $0.60-0.8$ &.$n$. & 3 \\
\hline & $\tau_{0}$ & $0.49 \geq 0.60$ & $0.55-0.60$ & $\tau_{0 .}$ & 2 \\
\hline$\sum$ & $\mathrm{p}$ & 0,4 & $0,49-0,55$ & $\tau$ & 2 \\
\hline$\infty x$ & $\mathrm{n}$ & 0.4 & $0.4-0.49$ & - & - \\
\hline & & 0.55 & $0,1-0,4$ & $p, n$ & 2 \\
\hline
\end{tabular}


стественно при использов нии предложенного метод н лиз сокр щ ется число ингредиентов в сост ве р створ, сниж ются з тр ты н приготовление, улучш ются условия контроля и упр вления его п р метров. конечном итоге обеспечив ется м ксим льно возможн я сохр нность коллекторских свойств пл ст . читыв я несложность лгоритм изложенного процесс, не предст вляет особой трудности созд ния прогр ммного продукт и использов ние последнего в отр слевых проектных институт х и обр зов тельных учреждениях.

екомендуемые виды полимеров

\begin{tabular}{|c|c|c|c|c|c|c|c|}
\hline 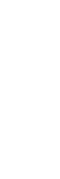 & 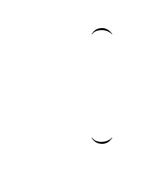 & 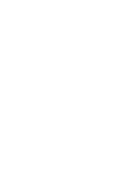 & 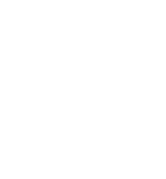 & 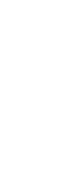 & 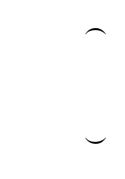 & 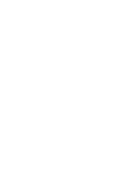 & 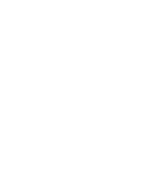 \\
\hline 1 & $\begin{array}{l}\text { с нт нов я } \\
\text { смол }\end{array}$ & $0,49 \ldots 0,55$ & $\mathrm{~T}, \tau_{0}, \mathrm{p}, \mathrm{n}$ & 7 & Biolam & $0,45 \ldots 0,65$ & $\mathrm{~T}, \tau_{0}, \mathrm{p}, \eta, \mathrm{n}$ \\
\hline 2 & иокс н- & $0,35 \ldots 0,50$ & $\mathrm{p}, \eta$, & 8 & IDVIS & $\begin{array}{c}0,7 \ldots 0,82 \\
0,59 \ldots 0,62\end{array}$ & $, \eta, p, \quad, \tau_{0}$ \\
\hline 3 & мм кс н & $\begin{array}{l}0,55 \ldots 0,65 \\
0,33 \ldots 0,50\end{array}$ & $, \eta, p, n$ & 9 & KEM-XD & $0,31 \ldots 0,35$ & $\eta, n$ \\
\hline 4 & $\begin{array}{l}.<0- \\
\text { бус» }\end{array}$ & $\begin{array}{l}0,6 \ldots 0,69 \\
0,4 \ldots 0,58\end{array}$ & $\eta, \mathrm{p}, \quad, \mathrm{n}$, & 10 & KEM-X & $\begin{array}{l}0,75 \ldots 0,82 \\
0,43 \ldots 0,65\end{array}$ & $\begin{array}{l}, \eta, p \\
\tau_{0, p}, n,\end{array}$ \\
\hline 5 & Polydis-DM & $0,25 \ldots 0,6$ & $\eta, p, \quad, n$, & 11 & VALBTOP & $0,46 \ldots 0,6$ & $\eta, p$ \\
\hline 6 & $\begin{array}{l}\text { Xanthan } \\
\text { Gum }\end{array}$ & $0,46 \ldots 0,52$ & $\tau_{0,} \mathrm{p}, \mathrm{n}$ & 12 & $\mathrm{XCD}$ & $0,2 \ldots 0,35$ & $, \mathrm{p}, \mathrm{n}$ \\
\hline
\end{tabular}

ким обр зом, из 18 р ссмотренных полимеров рекомендуется к внедрению 12 , предст вленных в т бл. 2.

писок аитер туры

1. енюшкин . . сследов ния и р зр ботк сост вов полис х ридных буровых р створов с нелинейными реологическими х р ктеристик ми: диссерт ция ... к ндид т технических н ук: 25.00 .15 / енюшкин ергей лерьевич; [ есто з щиты: юмен. гос. нефтег з. ун-т]. - юмень, 2012. - 120 с.: ил. ,61 13-5/471.

2. ксперимент льн я оценк эффективности полимерных компонентов буровых р створов для строительств скв жин н р йнем евере / . . . л ксин [и др.] // зов я промышленность. - 2012. - № 6 (677). - . 80-83.

3. овершенствов ние буровых р створов высокой плотности / . . . л ксин [и др.] // урение и нефть, 2013. № 2. - . 39-43.

4. вчинников собенности применения биополимерных ингибиров нных р створов для вскрытия продуктивных пл стов, содерж щих р зличные по химической ктивности глины (н примере месторождений $\mathrm{p}$ сноярского кр я) / . . вчинников, . . ковлев, . . ирин // урение и нефть. - 2014. - № 1. - . 44-46.

5. методу оценки эффективности применения буровых р створов для вскрытия продуктивных пл стов / . вчинников, . . ковлев, . . урб нов // троительство нефтяных и г зовых скв жин н суше и н море. -2014 - № 9. - . .40-44.

ведения об втор $x$

вчинников силий влович, д. т. н. профессор к федры «еотех», юменский индустри льный университет, 2. юмень, тел. 8(3452)390363,e-mail: geoteh@tgasu.ru

емененко н ст сия едоровн, ссистент к федры " урение нефтяных и г зовых скв жин» юменский индустри льный университет, г. юмень, тел. 8(3452)390363, e-mail: semenenko.83@mail.ru

вчинников вел сильевич, д. М. н., профессор оссийского геологор зведочного универcumem, г. оскв , тел. 89150504525, e-mail: ovchinnikovpv@mail.ru
Information about the authors

Ovchinnikov $\boldsymbol{V}$. P., Doctor of Engineering Sciences, Professor, Head of Department «Geotech», Industrial University of Tyumen, Tyumen, tel.8(3452)390363,e-mail: geoteh@tgasu.ru

Semenenko A. $\boldsymbol{F}$. , assistant of department «Drilling of oil and gas wells» Industrial University of Tyumen, Tyumen, tel.8(3452)390363, e-mail: semenenko.83@mail.ru

Ovchinnikov P. V., Doctor of Engineering Sciences, Professor of Russian State Geological Prospecting University, Moscow, tel. 89150504525, e-mail: ovchinnikovpv@mail.ru 